\title{
Forum
}

\section{The Attic Inscriptions: Education Project}

\author{
Peter Liddel \\ University of Manchester, Manchester, UK
}

In 'Greek Inscriptions: insights and resources in the classroom and beyond' (Liddel, 2017), I outlined some of the opportunities and perspectives that the study of inscriptions offers to learners getting familiar with the history and culture of ancient Greece at pre-university stage, and I considered the obstacles and opportunities that teachers and students face when trying to access them. That piece very much concentrated on inscriptions as a source for teachers and candidates of OCR's A-level Ancient History. In this essay I take a much broader approach to make a case for the relevance of ancient Greek inscriptions to pre-18 education, considering the ways in which they inform our understanding of Athenian society and contribute to the development of skills of analysis and evaluation of evidence. I highlight the growing significance of the Attic Inscriptions Online website, the Attic Inscriptions in UK Collections project, the newly-launched Attic Inscriptions: Education resource and the AIO YouTube channel to learners' critical engagement with sources for the ancient Greek world.

\section{The Epigraphic Habit in the Greek World}

Probably at some point at the start of the seventh century BC (c. $700 \mathrm{BC}$ ) the Greeks of the Eastern Mediterranean initiated one of the most enduring habits of antiquity: that of writing down Greek letters, words and sentences on hard surfaces, including rock, marble, metals, and ceramics. For the centuries that followed, Greeks across the Mediterranean, northern Africa, the Black Sea area and the Near East created inscriptions which performed a wide range of functions: they served as commemorations of the dead, gifts to the gods, inventories, accounts, treaties, decrees and laws; they appeared on lead and bronze tablets and plaques, fragments of pottery, statue bases and slabs of marble. The practice of putting inscriptions down on hard surfaces is known to modern scholars as the 'Epigraphic Habit'.

Some 200,000 ancient Greek inscriptions survive, dating to the period down to the sixth century AD. Many of them are broken or damaged, but those which do survive intact preserve for us direct evidence from the ancient world, unadulterated by modern editors. They are a wonderful source for the history of how city-states interacted with each other in terms of war, diplomacy and imperialism and tell us a great deal about the workings of religious practice, democratic administration, and the reality of daily life. We get a sense of the depth and detail of what they tell us about the real people of the ancient city when we consider that, of the 63,000

Author of correspondence: Peter Liddel, E-mail: Peter.Liddel@manchester.ac.uk

Cite this article: Liddel P (2022). The Attic Inscriptions: Education Project. Journal of Classics Teaching 23, 35-39. https://doi.org/10.1017/S2058631021000428 ancient Athenians who are known to us by name, around $90 \%$ of them have had their names revealed through inscriptions.

\section{Teaching with Ancient Greek inscriptions}

Inscriptions have great potential for providing insights into the interpretation of political, social and cultural history, the history of identity, gender, sexuality, all aspects of language and many other themes. Pedagogically, too, some of them have an advantage over our literary sources: their relative brevity means that, in translated form, they are quite manageable at all levels of teaching. Their combination of literary and (when attention is drawn to them) physical aspects, means that they have relevance to a wide range of learning styles. Like a coin or a single vase, they have an immediacy which lends itself to close focus. This means that an inscription can be treated as a snapshot of a particular moment in time and can open up discussion of a specific issue or question. They offer perspectives which are missing from the literary sources and sometimes contain versions of the past which lead us to ask new questions about the accounts of Thucydides and other writers: for instance, the Athenian treaty with the Rhegians (Figure 1) can be considered alongside Thucydides 3.86. Accordingly, in our Attic Inscriptions: Education resources (see below) we show how inscriptions might be used in the classroom to address not only the objectives of the specifications for A-level and GCSE Ancient History and Classical Civilisation but also those of the National Curriculum at Key Stages 1, 2 and 3.

Teachers and learners face obstacles and challenges when using Greek inscriptions: where to find them? How to translate them? How to explain them? How to interpret them? The Attic Inscriptions Online (AIO) website is a starting point to answering these questions.

\section{Attic Inscriptions Online (AIO) developments}

There survive some 20,000 Greek inscriptions from the ancient city of Athens. The mission of AIO, launched by Stephen Lambert in 2012, is to translate and offer explanatory notes on them in a fully-searchable, open-access, website; it makes Athenian inscriptions accessible to anyone interested and requires no knowledge of Greek language or prior experience of epigraphy. By the end of 2021, AIO, edited by Lambert, Polly Low, Peter Liddel and Chris de Lisle, will contain translations of more than 2000 inscriptions, with the input of an international team of more than 40 site contributors (from the UK, Netherlands, France, Italy, Germany, Greece, Switzerland, the US and Australia). AIO has special depth in its coverage of the inscriptions of the classical period, in particular the decrees of the fourth century BC; new 


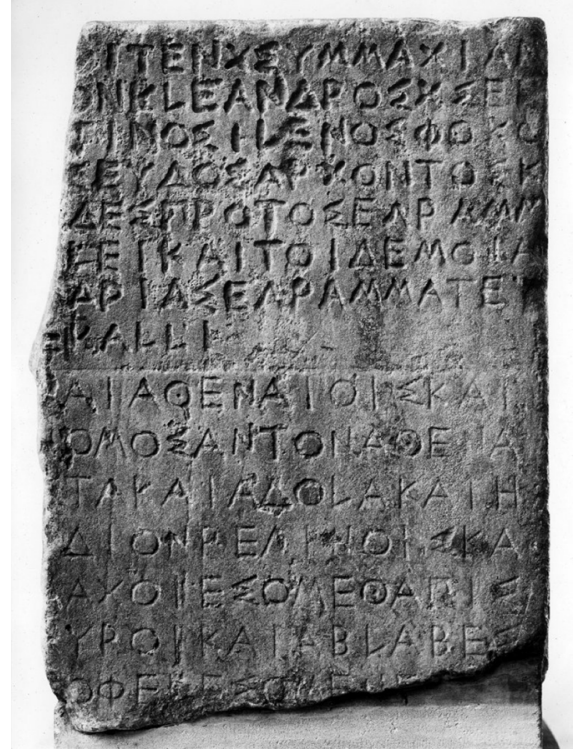

Figure 1. The Athenians' alliance with the people of Rhegion (south Italy), 433/2 BC. See AIUK 4.2 (BM, Decrees of Council and Assembly) no. 4. Image (c) Trustees of the British Museum.

launches take place periodically and are announced via social media. AIO hosts images of some inscriptions, and links to published versions of many more; it hosts also links to the Pleiades Project mapping website.

Teachers and learners can use AIO in many ways: for those who know what they are looking for, publications of individual inscriptions can be looked up using the browse function. Our emphasis, however, is on empowering teachers and learners to formulate and address historical questions by undertaking their own research on AIO. To this end, inscriptions can be browsed also by date, findspot, inscription type, monument type, original location or current location. This makes it possible to survey the kinds of inscription that were set up, for instance, at the sanctuary of Asklepios (Asklepieion) and to ask what they show about the activity of a particular cult or about attitudes towards a specific deity; similarly, one could explore the inscriptions from a specific location within Attica, such as Marathon or Piraeus. Subjects or themes can also be searched, so it would be possible to ask learners to 'research' on the subject of, for instance, the 'agora' or 'ephebes' and to analyse the results that came up. Or for the purposes of thinking about how Athenian officials were appointed to office, learners may be asked to search for words like 'allotted' or 'elected'; searching for the term 'accounts' would enable students to consider in depth the multi-faced notion of accountability in ancient Athens. In the future, an Advanced Search will allow students to limit their searches by date, inscription type, monument type, original location or current location.

A guide to the use of AIO for teaching purposes can be found in AIO Papers 10, published on the AIO website; AIO Papers 8, studying the Chalkis decree and Tribute Reassessment decree of Thoudippos, is aimed specifically at teachers of the current A-level specifications.

\section{Attic Inscriptions in UK Collections (AIUK)}

In the period from the 17 th century to the early 19 th centuries $\mathrm{AD}$, wealthy travellers from Britain explored the cultural centres of Europe in an early form of the 'Gap Year', the 'Grand Tour'. Many of those who reached the eastern Mediterranean turned their attention to collecting artefacts (vases, coins, sculpture, architectural elements, statue bases, marble slabs) which had been produced in the classical era. Particularly sought after were those objects which bore inscriptions written in Latin, Greek and other ancient languages. As a consequence of these explorations, some 225 ancient Athenian inscriptions were brought to the UK, and the majority of them are still currently held in collections dotted around the country. More than half of them are kept at the British Museum, but there are substantial accumulations also at the Fitzwilliam (Cambridge) and Ashmolean (Oxford) and smaller ones in other public museums in Newcastle, Leeds and Edinburgh, at National Trust properties (Mount Stewart, Petworth House, Lyme Park) and private properties (including Broomhall, Chatsworth and Brocklesby). Hosted on the AIO website, the Attic Inscriptions in UK Collections project (2017-2022) is currently engaged in examining these inscriptions, editing them and publishing open-access texts, translations and commentaries on them via our open-access AIUK website (see Figure 2).

Our programme of AIUK-related activities over the duration of our project has produced a series of lectures for the Workers' Educational Association, talks and seminars at the Fitzwilliam and Ashmolean Museums, training for gallery lecturers and front-house volunteers at the Ashmolean, and a British Museum study day and CPD event for teachers in October 2021. We have produced a set of notes (currently available from the author via email) for visitors to the British Museum and the Ashmolean which will help them identify and interpret Athenian inscriptions on display in those museums.

The goal of our project is to promote public understanding not only of these inscriptions but also of the routes by which they came to the UK and in particular the importance of wealth, imperial influence and British diplomatic ties in bringing the material to the UK. We hope that our research and associated publications will facilitate teachers' and learners' engagement with these collections.

\section{Attic Inscriptions: Education}

In June 2021 we launched our Attic Inscriptions: Education (AIE) website (Figure 3). AIE resources illustrate the relevance of ancient Athenian inscriptions, especially those of the classical period (the fifth and fourth centuries BC, c. 500-300 BC), to pre-18 education in the UK and beyond. We aim to support teachers who wish to embed translated Greek inscriptions into their teaching as a way of captivating their students' imagination and fostering enthusiasm for the ancient Greek world.

These resources, consisting of teachers' notes and slides for classes, underline the textual and visual potential of inscriptions for those engaged with learning about ancient Greek history and civilisation. The idea of an inscription being carved and read 'in real life' is a way of fostering the curiosity of students about the past. Accordingly, through inscriptions, learners benefit from the bringing to life of the ancient world, perhaps in a way that helps it seem less abstract and more immediately accessible. Inscriptions are flexible and adaptable in the classroom: their relative conciseness and free-standing nature makes them easily accessible; additionally, the open-access availability of AIO means that students have the opportunity to conduct independent research using the website (see above). Moreover, inscriptions suit those students who enjoy paying close attention to detail: looking carefully at words and phrases underscores sophisticated comprehension of important historical issues. At the same time, we hope that exposing students at pre-18 level to inscriptions will 
empires; characteristic features of past non-European societies; achievements and follies of mankind' (Department for Education, 2014). One of the achievements of mankind is, undoubtedly, the invention of writing and numeracy. Furthermore, the collective history of ancient Athenian inscriptions (alongside other antiquities) makes them relevant to the history of imperialism: imperial power (and diplomatic influence) in the 18th and 19th centuries was one of the currents which supported the import of antiquities and inscriptions from the Eastern Mediterranean into the UK. Both aspects are explored in our Key Stage 3 resources, which discuss how ancient Athenian inscriptions came to the UK, what they tell us about ancient Greek literacy, numeracy and art; they end with focus on the History of Medicine.

Our Key Stage 4 resources show how Athenian inscriptions are relevant to the specifications of GCSE-level classical subjects. The AIE Classical Civilisation notes and classroom slides address a wide range of the Greek cultural aspects of the OCR GCSE curriculum, covering the Thematic Studies on Myth and Religion (Herakles, priests and priestesses, animal sacrifice, death and burial) and Women in the Ancient World (young women, women at home, women and religion; see Figure 4) and the Literature and Culture element on War and Warfare (equipment and impact on society).

Ancient sources are central to the OCR Ancient History GCSE specification and especially the Depth Study, which is introduced with the statement that 'the focus will be on the critical use of ancient source material in investigating and assessing historical questions, problems and issues.' Inscriptions constitute ideal material for this endeavour and can be given to students in bite-sized portions. The AIE GCSE Ancient History notes and classroom slides focus upon a number of inscriptions which are relevant to the Depth Study on Athens in the Age of Pericles, $462-429 B C$. They are central to the following topics: the workings of Athenian democracy, Pericles' foreign policy (including Delian League), cultural and religious life in the age of Pericles; women (questions of citizenship; role and position of women in daily life and marriage). Our material aims to address a wide range of aspects of the GCSE curriculum, covering culture, religion and military

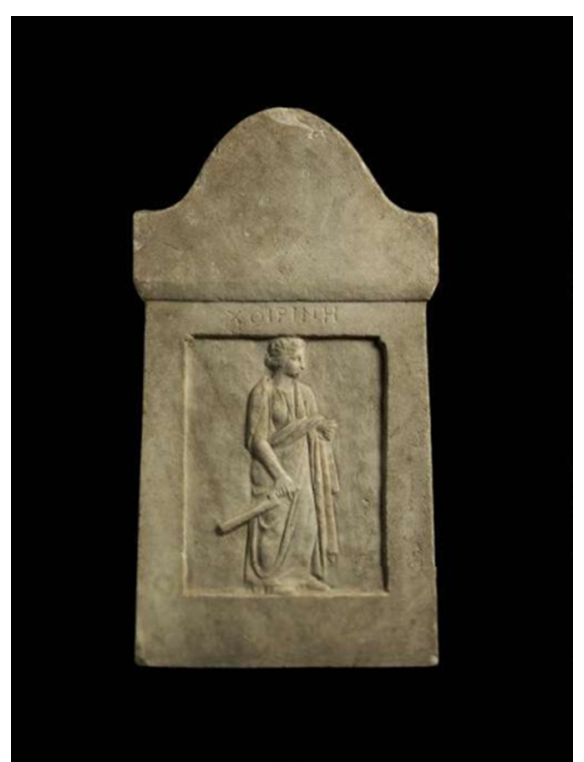

Figure 4. Grave marker of Choirine. From Athens, fourth century BC. She holds a key, indicating that she was a priestess. BM 2007,5001.1. Image (c) Trustees of the British Museum. affairs. We try to draw upon inscriptions that derive chronologically from the 'Periclean' period of Athenian history.

The AIE notes and slides for A-level Classical Civilisation focus on supporting evaluation and analysis of classical inscriptions in their social, historical and cultural context and providing information about relevant secondary scholarship pertaining to the OCR specifications for A-level Classical Civilisation. Our resources engage at depth with the Greek Religion (H408/31) component. Given the centrality of inscriptions to what we know about cult activity and the workings of Athenian democracy, this should come as no surprise. In our notes on the Democracy and the Athenians (H408/34) component, we suggest also that inscriptions can be used to substantiate the three-fold characterisation of popular rule and isonomia put into the mouth of the Persian Otanes by Herodotus (3.80). Approached in this way, inscriptions not only give us perspectives into the details of history but also help students to develop a critical approach to the literary sources. Decorative elements of Athenian funerary monuments are relevant to the component on Greek Art (H408/24). The fact that Athenian inscriptions demonstrate engagement with individuals of non-Greek extraction means that there is epigraphical material relevant to the Invention of the Barbarian (H408/23) component.

Inscriptions of the fifth century BC are, alongside Thucydides, the main source for our understanding of inter-state relations of Greece (see above, Figure 1) in this period and in particular in the workings and nature of the Delian League and Athenian Empire. Accordingly, the AIE notes and slides for A-level Ancient History focus upon the OCR Ancient History A-level components relevant to Greek history in the fifth century BC: 'Relations between Greek states and between Greek and non-Greek states, 492-404 BC' and the Depth Study, 'The Politics and Culture of Athens, c.460-399 BC. Carefully interpreted, inscriptions offer us important insights into the Athenians' treatment of their allies and those allies' likely experiences of Athenian hegemony.

Our hope is, therefore, that through the AIE resources, inscriptions can inform and deepen engagement with ancient Greek culture in the teaching of classical subjects in translation at all levels. To the resources already described, teachers also might find interesting the AIO YouTube channel, which contains videos about individual inscriptions or groups of inscriptions, mostly in UK Collections. Its recordings are of varied length and depth, and teachers may find especially helpful our short videos on the inscriptions at the Ashmolean or those on other funerary monuments in UK collections useful as conversation starters for classes.

\section{Attic Inscriptions: Education CPD event}

The AIO CPD event on $5^{\text {th }}$ June 2021, gave its delegates (39 of them, from across the UK, a few from Greece, one from Brazil and another from Canada) and contributors a preview of the AIE website. The event featured three contributors from AIUK Editors: Polly Low discussed the centrality of inscriptions to the interpretation of the Delian League/Athenian empire, emphasising their perspectives into its development, nature and ideology. Chris de Lisle's talk explained 'How to Date an Athenian Inscription', demonstrating the significance of textual content as well as alphabet, letter forms and style. Robert Pitt focused upon Athenian funerary monuments at the British Museum, exploring the breadth of their forms and relevance to the study of classics in translation. These three contributions will be recorded and made available on the AIO YouTube channel. 
On the same occasion, we were fortunate to have the opportunity to hear the perspectives of experienced schoolteachers. Karen Stears pointed out some of the qualities of private inscriptions (such as graffiti, curse-tablets, ostraka) that make them both accessible to different types of learner and attractive ways of approaching difficult topics like sexuality. Athina Mitropoulos demonstrated in detail the ways in which Athenian inscriptions speak to the specifications for the A-level Classical Civilisation on Greek Religion. Anne Wright made suggestions on how to get students to engage with the visual aspects of funerary monuments by creating jigsaw puzzles out of good-quality images. Three teachers of classical subjects at GCSE (Sophie Evans, Liam Holian, Esther Hyde) offered valuable perspectives on using inscriptions in the classroom, noting in particular their usefulness in helping learners to see history through the eyes of named individuals. Matt Ingham and Kat Mawford considered inscriptions from the point of view of teaching younger learners and provided reflections on their experiences as organisers of the Athena's Owls project: as they observed, inscriptions might be a starting point for getting pupils to look around for inscriptions in their own locality when engaging with the Geography programme of Key Stages 1 and 2. Charlie Andrew discussed the work of Classics for All in introducing young learners to the ancient written word, such as the curse tablets from Roman Bath. Nike Makres' talk highlighted a common element between the contemporary Greek and UK national curricula: the shortage of inscriptions, while highlighting their great potential to engage with the specifications in both countries.

\section{Future directions}

The AIE CPD highlighted important potential directions in which the project might move in the future: certainly, the production of further high-quality, learner-friendly, videos on a range of topics, perhaps on individual inscriptions, is a priority. As a document which pertains to an epoch-making event and was crucial to the construction of Athenian, Greek and Western identity, the recentlypublished Erechtheid casualty list of the dead from the Battle of Marathon (discovered in the excavation of Herodes Atticus' Arcadian villa: SEG 53.354) is a potential object of focus and one which resonates with modern war memorials that can be found across the UK. Other inscribed objects, such as ostraka, curse-tablets and rock-cut graffiti would represent a new direction for a project which has, for the most part until now, concentrated upon writing inscribed on marble objects. A lead letter, discovered in the Athenian agora in 1971, written by the enslaved Lesis to Xenokles and his mother complaining about his treatment at the hands of his masters, is interesting in the context of the history of slavery: it provides a valuable testimony of the oppressed and an insight into a dark aspect of Athenian culture. Like many other inscriptions, it illuminates an underexplored and murky area of Athenian history. Such is the potential of inscriptions to make a contribution to our understanding of the ancient Greek world, and that is why they should be accessible to as wide an audience as possible.

\section{Attic Inscriptions links}

Attic Inscriptions Online: https://www.atticinscriptions.com/ Attic Inscriptions Papers: https:/www.atticinscriptions.com/papers/ Attic Inscriptions in UK Collections: https://www.atticinscriptions.com/ papers/aiuk/

Attic Inscriptions: Education: https://www.atticinscriptions.com/education/ Attic Inscriptions Online Youtube: https://www.youtube.com/channel/ UCoavdbYcrROujQD7qITwWMQ

\section{Other websites of interest}

Ashmolean Latin Inscriptions Project: https://www.ashmolean.org/article/ ashmolean-latin-inscriptions-project

Athenian Agora Excavations: http://www.agathe.gr/

British Museum Collections: https://www.britishmuseum.org/collection

Pleiades Project: https://pleiades.stoa.org/home

\section{References}

Department for Education (2014). The National Curriculum in England: Key Stages 3 and 4 Framework Document. Available online: https://www.gov.uk/ government/publications/national-curriculum-in-england-framework-forkey-stages-1-to-4/the-national-curriculum-in-england-framework-for-keystages-1-to-4\#the-national-curriculum-in-england (accessed 25h June 2021).

Liddel, P. (2017). Journal of Classics Teaching 18, pp. 43-47. 